\title{
SIMULASI PENCAHAYAAN ALAMI PADA GEDUNG PROGRAM STUDI ARSITEKTUR UNIVERSITAS MALIKUSSALEH
}

\author{
Atthaillah $^{1, *}$, Muhammad Iqbal $^{2}$, Iman Saputra Situmeang ${ }^{3}$ \\ 1,2,3 Program Studi Arsitektur, Fakultas Teknik, Universitas Malikussaleh, Jalan Samudera, \\ Lancang Garam, Lhokseumawe, 24351 \\ *atthaillah@unimal.ac.id
}

\begin{abstract}
ABSTRAK. Penelitian ini melakukan investigasi performa pencahayaan alami pada Gedung Program Studi Arsitektur Fakultas Teknik (PAFT) Universitas Malikussaleh.Berdasarkan observasi pada gedung PAFT, ruangan-ruangan pada bangunan cenderung gelap dan memakai bantuan pencahayaan buatan walaupun pada siang hari, serta memiliki lahan sempit sehingga cahaya alaminya terhalang oleh bangunan perimeter. Tujuan dari penelitian ini adalah untuk menganalisa performa pencahayaan alami khususnya faktor pencahayaan alami (daylight factor) pada gedung PAFT dan memberikan solusi desain untuk meningkatkan performa pencahayaan alaminya. Metode penelitian dilakukan melalui simulasi Komputer (computer simulation) dengan software Velux Daylight Visualizer versi 2.0 untuk perhitungan faktor pencahayaan alami. Hasil menunjukkan bahwa permasalahan disebabkan oleh beberapa faktor diantaranya adalah kedalaman ruang, posisi ruang, pemilihan material bukaan, penempatan bukaan yang tidak sesuai, kondisi sekitar bangunan (penghalang bangunan), dan Window Wall Ratio (WWR) yang kurang memadai. Selanjutnya, penelitian ini memberikan solusi seperti meningkatkan WWR (menambah dan memperluas bukaan), mengganti warna interiordengan warna yang lebih cerah seperti warna putih, mengganti material bukaan dengan nilai Tvis lebih tinggi $(0,850)$ dan menambahkan shading devices pada tempat-tempat yang dianggap membutuhkan untuk menghindari efek silau berlebihan dalam ruangan.
\end{abstract}

Kata kunci:Pencahayaan Alami, Faktor Pencahayaan Alami, Velux Daylight Visualiser 2.0, Simulasi Komputer

ABSTRACT. This paper investigated daylightperformancewithin Gedung Program Studi Arsitektur Fakultas Teknik (PAFT) Universitas Malikussaleh. As observed, ononehand, spaces within the building relatively dark and it utilised electric lighting during working hours, on the other hand, it was madeworse by narrowing site surrounded with perimeter buildings at close distances. The aim of this study was to analyse daylighting performance within PAFT building, particularly, daylight factor (DF). Furthermore, this research offered some solutions to improve daylight performance within PAFT building. Computer simulation were adopted with Velux Daylight Visualizer Version 2.0 for DF calculation. Result showed, majority of spaces within PAFT building did not meet standard as required by Standar Nasional Indonesia (SNI). The causes for the condition were depth of spaces, mispositioning of particular spaces within PAFT building, incorrect glass selection for openings, inappropriate opening positioning, reasonably close distance of adjacent building and insufficient window wall ratio (WWR). The possible solutions forthesituation wereby increasing the WWR, change interior into a brighter color such as white, replaced all of glasses with higher Tvis values (0.850) and provided shading devices where appropriate to reduce glare within the rooms.

Keywords: Daylighting, Daylight Factor, Velux Daylight Visualiser 2.0, Computer Simulation

\section{PENDAHULUAN}

Pencahayaan alami yang diterapkan pada bangunan memiliki banyak manfaat, baik dari segi visual maupun penghematan pemakaian energi. Selain berdampak pada performa bangunan, pencahayaan alami dapat mempengaruhi produktivitas dan kesehatan manusia misalnya, membantu memproduksi vitamin $\mathrm{D}$, menekan kolestrol, mengurangi resiko kanker, meningkatkan sirkulasi darah, dan banyak manfaat lainnya [1]. Untuk itu, menerapkan pencahayaan alami pada bangunan harus di perhatikan dengan baik agar menghasilkan performa pencahayaan alami yang baik pada bangunan. Manfaat pencahayaan alami ini sangat dibutuhkan terutama pada bangunan yang berada dibawah lembaga pendidikan terutama untuk meningkatkan performa produktivitas seperti Gedung Program Studi Arsitektur Fakultas Teknik (PAFT), Universitas Malikussaleh.

Gedung PAFT Universitas Malikussaleh, berlokasi di Jl. Samudera Baru yang berganti nama menjadi Jl. Sultanah Nahrasiyah Kota Lhokseumawe Provinsi Aceh, adalah salah satu bangunan yang harus memperhatikan 
kinerja pencahayaan alaminya, mengingat bangunan ini adalah bangunan yang dibuat untuk sarana pendidikan arsitektur. Dari hasil observasi penulis, ruangan pada bangunan ini cenderung gelap pada siang hari, memiliki lahan yang sempit yang pencahayaan alaminya terhalangi oleh bangunan-bangunan lain. Bangunan ini juga memakai bantuan pencahayaan buatan walaupun pada siang hari. Kebutuhan akan pencahayaan alami yang memadai pada bangunan ini perlu di teliti agar memenuhi standar minimum pencahayaan alami berdasarkan berbagai kegunaan ruangnya. Meskipun bangunan ini sudah di bangun, tetapi kondisi pencahayaan alaminya harus di evaluasi untuk mendapatkan performa gedung PAFT yang memenuhi standar pada pencahayaan alami.

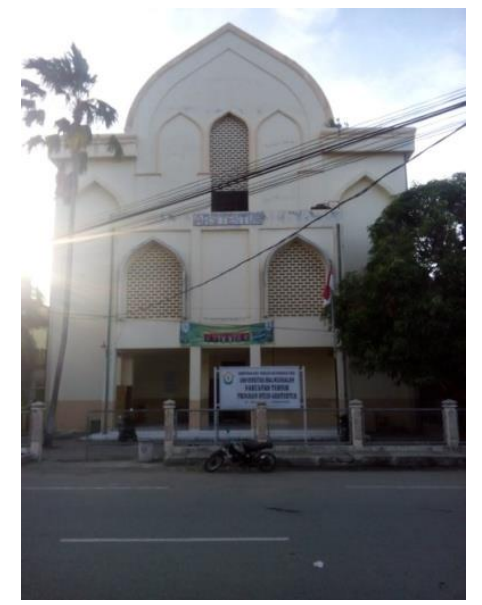

Gambar 1. Gedung Prodi Arsitektur Universitas Malikussaleh

(Sumber: Penulis, 2017)

Pencahayaan alami yang diteliti pada bangunan PAFT ini adalah faktor pencahayaan alami atau yang lebih sering dikenal dengan istilah daylight factor (DF). Dalam pengukuran faktor pencahayaan alami ini, peneliti menggunakan metode dengan simulasi komputer. Pengukuran langsung akan sulit mendapatkan hasil yang lebih akurat dan waktu penelitiannya akan berlangsung lama. Selain lebih mudah dalam menentukan pengukuran dengan simulasi, pengukuran dengan metode ini pun akan mendapatkan analisa dan hasil yang lebih akurat berdasarkan kondisi bangunan, karena dengan metode simulasi pemodelan dapat merepresentasikan material, tekstur bangunan dan luas bidang permukaan bangunan dengan baik [2]. Penelitian dengan simulasi komputer ini juga akan mempermudah peneliti memberikan solusi desain untuk ruangan yang tidak memenuhi standar agar bisa terpenuhi dengan memodifikasi ruangan atau bukaan pada bangunan. Metode ini menjadi pilihan agar mendapatkan hasil yang lebih baik dalam pengukuran faktor pencahayaan alami pada gedung PAFT.

Selanjutnya, studi ini juga memiliki batasanbatasan yaitu, pertama, pencahayaan yang diukur adalah faktor pencahayaan alami (daylight factor) dengan metode simulasi. Kedua, penelitian ini akan memaparkan hasil simulasi dan mengevaluasi dengan standarisasi yang ada. Terakhir, kondisi ruangan yang diukur dalam kondisi kosong.

\section{Pencahayaan Alami}

Pencahayaan alami adalah pencahayaan yang memiliki sumber cahaya yang berasal dari matahari. Lippsmeier mengatakan bahwa matahari merupakan satu-satunya sumber cahaya alami yang menghasilkan cahaya alami (daylight) dengan disertai energi cahaya dan energi panas. Energi cahaya yang dihasilkan oleh sinar matahari akan berpengaruh pada kenyamanan visual didalam bangunan, sedangkan energi panas akan berimplikasi pada kenyamanan termal [3].

Pencahayaan alami dapat dimasukkan melalui bukaan. Lechner menyatakan bahwa cahaya yang masuk melalui bukaan berasal dari beberapa sumber yakni, sinar matahari langsung, langit cerah, awan atau pemantulan bawah dan bangunan sekitarnya [4]. Selanjutnya, Mediastika mengatakan bahwa pencahayaan alami dalam bangunan atau ruangan masuk melalui bidang bukaan atau bidang tertutup yang transparan. Bidang ini bisa diletakkan dengan posisi horizontal atau semi horizontal seperti pada atap, dan secara vertikal atau semi vertikal pada dinding. Jenis bukaan yang akan digunakan sangat bergantung pada banyak faktor [1]. Misalnya, kaca pada bukaan menunjukkan banyaknya cahaya yang terlihat lewat lapisan (transmisi). Angka transmisi pada bukaan kaca bervariasi dari 0,9 untuk kaca bening dan kurang dari 0,1 untuk kaca yang pantulannya tinggi dan kaca berwarna [4].

\section{Faktor Pencahayaan Alami (Daylight Factor)}

Daylight faktor (DF) adalah rasio iluminasi dalam ruang dengan luar ruangan pada titik tertentu dalam sebuah ruangan yang dinyatakan dalam satuan persentase[5]. Faktor pencahayaan alami memiliki tiga kompenen yaitu, pertama, komponen langit (faktor langit) merupakan pencahayaan langsung yang berasal dari cahaya langit. Kedua, komponen 
refleksi luar (faktor refleksi luar) merupakan komponen pencahayaan akibat pantulan objek sekeliling bangunan. Terakhir, komponen refleksi dalam (faktor refleksi dalam) yang merupakan komponen pencahayaan yang merupakan refleksi dari objek-objek yang bera dalam sebuah ruangan [5].

\section{TREN PENCAHAYAAN ALAMI DALAM ARSITEKTUR}

Mahaputri melakukan pengamatan pencahayaan alami dengan dengan metode simulasi pada kasus objek bangunan pendidikan [2]. Simulasi ini dilakukan dengan membuat perbandingan antara hasil modifikasi ruang terhadap kondisi ruang yang sebenarnya. Penelitian ini dilakukan pada sebuah ruang fasilitas pendidikan dengan fungsi ruang sebagai perpustakaan. Pencahayaan yang diteliti adalah iluminance dan daylight factor dengan hasil memenuhi standar baik dari kondisi ruang awal ataupun setelah melakukan modifikasi. Penelitian ini bertujuan untuk mengetahui pengaruh desain bangunan terhadap kinerja bangunan khususnya pada pencahayaan alami, dengan menekankan bahwa dalam perencanaan dan perancangan dibantu dengan metode simulasi sangat efektif untuk mewujudkan desain yang optimal.

Selanjutnya, Chandra dan Amin melakukan penelitian mengukur pencahayaan alami dan buatan dengan menentukan waktu proses pengukuran [6]. Pengukuran ini menggunakan alat Lux Meter dan dengan alat simulasi software Ecotect. Penelitian ini dilakukan pada sebuah ruang studio dengan fungsi ruang sebagai tempat menggambar. Bagian pencahayaan alami yang diukur adalah tingkat iluminasi, dan selanjutnya melakukan simulasi pada pencahayaan buatan. Hasil pengukuran pencahayaan pada ruangan tersebut tidak memenuhi standar. Pada penelitian ini, penulis memberikan solusi yaitu, mengubah jenis lampu untuk pencahayaan buatannya. Dengan demikian, pencahayaan alami ditambah dengan pencahayaan buatan akan dapat memenuhi standar pencahayaan untuk sebuah ruang dengan kegiatan yang mendetail, seperti menggambar detail.

Pencahayaan alami dapat mempengaruhi performa visual pada bangunan. Pengaruh ini dijadikan alasan banyak peneliti untuk mendapatkan hasil visual yang efektif ketika melakukan penelitian, terutama pada bagian interior bangunan. Performa visual dari pencahayaan alami dapat mempengaruhi kualitas warna interior, tekstur dan permukaan interior. Yuniar et al. melakukan penelitian dengan metode kuantitatif dan kualitatif dengan menekankan pemahaman dan memberikan hipotesis pada penelitian, serta melakukan simulasi dengan software Ecotect [7]. Penelitian dilakukan pada gedung rektorat UPI (Villa Isola) yang berfungsi sebagai kantor. Pencahayaan alami yang diteliti adalah tingkat iluminasi dan menganalisis warna dan tekstur pada interior bangunan, dengan hasil bahwa Villa Isola kurang memenuhi standar minimum pencahayaan alami.

Penelitian pencahayaan alami yang umumnya dilakukan adalah menentukan langit eksisting, misalnya Indonesia yang memiliki kondisi langit eksisting tropis. Penelitian ini menggunakan waktu tertentu pada saat melakukan pengukuran. Hal ini dimaksudkan untuk mendapatkan hasil dengan kondisi langit yang diinginkan, baik dalam kondisi terbaik maupun dalam kondisi langit terburuk. Samodra melakukan penelitian pencahayaan alami dengan metode simulasi softwareSuperlite[8]. Simulasi ini dilakukan dengan menentukan langit eksisting tropis dan penelitian berdasarkan waktu. Penelitian dilakukan pada bangunan pendidikan yaitu di ruang dosen yang berfungsi sebagai kantor. Pencahayaan alami yang diteliti adalah illuminance dan daylight factor dengan hasil memenuhi standar dan memberikan solusi untuk menghindari silau pada ruangan. Pada penelitian ini penulis memberikan rekomendasi seperti, menambahkan shading overhang untuk menghindari silau, mengurangi atau menghilangkan overhang untuk memenuhi standar minimal daylight factor, dan menambahkan nilai transmisi jendela dan refleksi elemen ruang.

Penelitian tentang pencahayaan alami yang sangat erat kaitannya dengan penelitian ini adalah studi yang dilakukan oleh Nurhaiza dan Lisa [9]. Studi tersebut fokus pada pengukuran ketersediaan cahaya alami pada beberapa ruang kegiatan perkuliahan di gedung PAFT. Metode yang digunakan adalah pengukuran iluminasi cahaya dengan menggunakan luxmeter pada satu waktu, 5 Desember 2015, mulai dari pukul 08.00 sampai pukul 16.00. Hasil penelitian tersebut menyimpulkan bahwa ketersediaan cahaya alami belum optimal pada ruang-ruang yang diteliti. Hasil dari penelitian ini tidak bisa mewakili profil penerimaan cahaya alami pada gedung PAFT sehingga belum bisa dipastikan bahwa di waktu yang lain akan memiliki iluminasi yang memadai ataupun tidak memadai. 
Pembahasan diatas jelas terlihat bahwa, pertama, analisa pencahayaan alami tidak ada yang dilakukan dengan Velux Daylight Visualizer sebagai software simulasi. Kedua, penelitian tentang pencahayaan alami pada gedung PAFT, Universitas Malikussaleh yang dilakukan sebelumnya hanya terbatas pada pengukuran nilai illuminance pada satu waktu tertentu saja dan tidak pada keseluruhan ruangan, penelitian tersebut juga tidak merekomendasikan strategi-strategi yang bisa digunakan untuk memperbaiki performa cahaya alami pada ruang-ruang yang diteliti. Terakhir, hanya sebahagian kecil dari peneliti yang memberikan solusi desain secara arsitektur yang konkrit seperti yang dilakukan Samodra [8]. Untuk itu penelitian ini akan mencoba melingkupi hal-hal yang belum menjadi fokus tersebut.

\section{METODE PENELITIAN}

Metode yang digunakan adalah studi simulasi komputer (computer simulation). Mahaputri mengatakan bahwa metode ini banyak memberikan keuntungan, terutama dalam mengatasi kendala kebergantungan pada kondisi cuaca, waktu studi dan kondisi lingkungan lain yang ditemui pada penggunaan studi model fisik [2]. Bahkan, dalam mewakili skala material, tekstur, dan luasan bidang permukaan, penggunaan simulasi komputer terbukti lebih akurat. Secara umum, simulasi komputer dapat didefinisikan seperti pada kutipan berikut.

"...the representation of the behavior or characteristics of one system through the use of another system, especially a computer program designed for the purpose." [10]

Jadi simulasi yang dimaksud pada studi ini adalah imitasi keadaan nyata kedalam bentuk digital. Pada studi ini simulasi akan menggunakan softwareGoogle Sketchup $B^{\circledR}$ versi 8.0, Velux Visualizer $\AA$ versi 2.0 untuk mensimulasikan kondisi faktor pencahayaan alami pada bangunan Prodi Arsitektur Universitas Malikussaleh serta LBNL Window 7.3® untuk membantu mencari nilai Tvis material kaca.

SoftwareVelux Daylight Visualizer2.0B sudah mendapatkan persetujuan atau Validation dari CIE (International Commission on Illumination). Pengujian pada software ini bertujuan untuk menguji keakuratan software dalam menghitung pencahayaan alami dan kualitas rendering yang terdapat pada software. Dari pengujian ini CIE menyimpulkan bahwa Velux
Visualizer $2.0 B$ hanya memiliki $1,63 \%$ error rata-rata yang terjadi pada pengujian, sedangkan error maksimum 5,54\%. Dengan pengujian tersebut Velux Visualizer 2.0B dinyatakan dapat memprediksi tingkat akurat pencahayaan alami [11].

Selanjutnya, teknik pengumpulan data yang dilakukan, pertama, obesrvasi kondisi eksisting yang ada pada objek penelitian. Kedua, survei dan pengukuran langsung untuk permodelan digital. Ketiga, dokumentasi hasil pengukuran dalam bentuk file digital. Selanjutnya data yang diperoleh disebut dengan data primer. Tahap berikutnya adalah mengkaji data sekunder diperoleh melalui literatur terkait dengan topik penelitian ini.

Objek penelitian yang dimodelkan secara digital menggunakan Google Sketch Up® versi 8.0 harus memperhatikan beberapa kriteria agar simulasi dapat dijalankan dengan benar di Velux Visualizer versi 2.0B. Ada dua kriteria yang harus diperhatikan dalam permodelan. Pertama, membuat modeling bangunan sesuai dengan kondisi yang ada, dengan memperhatikan material dan penamaan pada material pada model untuk mempermudah simulasi pada Velux Visualizer 2.0®. Kedua, Menentukan bidang kerja pada setiap ruang didalam bangunan. Bidang kerja ini digunakan sebagai titik ukur pada perhitungan faktor pencahayaan alami.

Setelah melakukan permodelan dengan benar maka selanjutnya adalah melakukan proses import ke Velux Visualiser2.0B. Adapun halhal yang patut menjadi pertimbangan adalah, pertama, Ukuran dalam Velux Visualizer $2.0{ }^{\circledR}$ ditentukan dalam millimeter $(\mathrm{mm})$. Kedua, Pada bagian atas ada pilihan "surface" untuk mengedit material pada bangunan dan "zona" untuk bidang kerja. Pengeditan ini harus sudah di atur terlebih dahulu pada program Google Sketchup ${ }^{\circledR} 8$ terutama pada bidang kerja dan pemilihan nama material. Ketiga, Transmisi untuk bukaan kaca pada gedung Prodi Arsitektur yang diambil datanya dari softwareWindow 7.3®, LBNL (Lawrence Barkeley National Laboratory). Keempat, Bagian "Location" dilewatkan karena dalam faktor pencahayaan alami berada pada situasi langit yang kondisinya merata, dan kondisi dalam bangunan sama dengan kondisi di lapangan terbuka. Kelima, "Camera" pilih "set area" untuk menentukan bagian yang akan dilihat tingkat faktor pencahayaan alaminya. Pada bagian "set area" atur "view height"sesuai standarisasi. Terakhir, Pada bagian "Render" tentukan pilihan daylight 
factor, bagian ini juga bisa menentukan kualitas tampilan render yang diinginkan.

Metode render yang digunakan Velux Visualizer adalah photon map. Iversen et almengatakan bahwa Photon map adalah render di dua arah denganmenelusuri(tracing) jalur pencahayaan baik dari sumber cahaya maupun dari sudut pandang [12]. Sumber cahaya akan mendapatkan energi foton. Energi foton ini akan membawa jumlah cahaya dari sumber cahaya dan terjebak dalam struktur data hal tersebut disebut photon map.

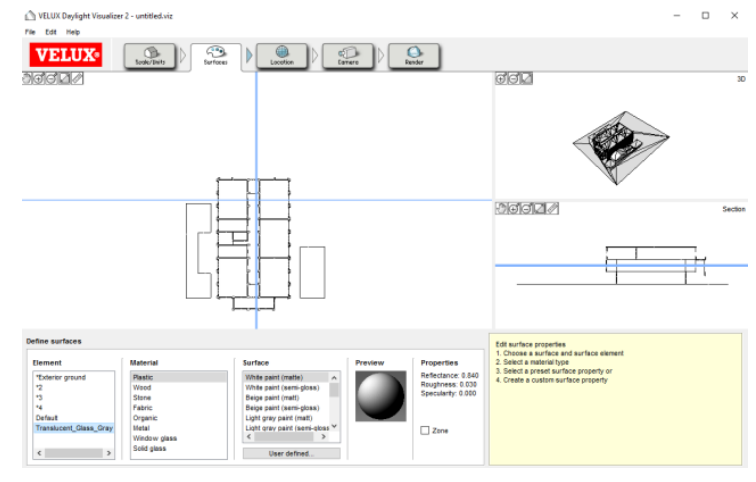

Gambar 2. Antar muka Velux Visualiser $2.0 \AA$ (Sumber: Penulis, 2017)

Hasil dari render Velux Visualizer $2.0 \AA$ menampilkan kondisi faktor pencahayaan alami pada ruangan dengan memaparkan DF rata-rata yang menjadi acuan untuk kualitas faktor pencahayaan alami pada ruangan tersebut. Hasil dari faktor pencahayaan alami dinyatakan dalam persen (\%). Pada penelitian ini, hasil simulasi akan ditampilkan dengan Iso Contour dan False Colour. Iso Contour adalah hasil render yang ditampilkan dengan kontur cahaya yaitu, dengan menampilkan garis-garis berwarna yang menyatakan nilai ataupun tingkat cahaya pada hasil simulasi. Garis kontur dimulai dari warna merah (tingkat pencahayaan tinggi) sampai dengan warna biru (tingkat pencahayaan rendah). Sedangkan untuk False Colour merupakan hasil render yang menampilkan gradasi warna pada area yang disimulasikan untuk memperjelas tingkat pencahayaan pada area tersebut. Warna yang ditampilkan merupakan nilai dalam pencahayaan, misalnya gradasi warna biru memiliki tingkat pencahayaan $0.00 \%$ sampai dengan $1.00 \%$.

Dalam pengukuran daylight factor dengan metode simulasi terdapat beberapa hal yang harus diperhatikan. Seperti menentukan kondisi langit, titik ukur (bidang kerja) standar ataupun nilai faktor pencahayaan alami yang di rekomendasikan untuk ruangan yang disimulasikan. Kondisi langit pada simulasi pencahayaan alami berada pada kondisi langit berawan (overcast sky). Kondisi langit ini digunakan dalam software Velux Visualizer 2.0 sebagai standar (default). Kensek dan Suk mengatakan bahwa model langit berawan (100\% tertutup) telah banyak digunakan untuk menghitung faktor pencahayaan alami [13]. Kondisi ini digunakan untuk menghitung faktor pencahayaan alami dalam skenario terburuk.

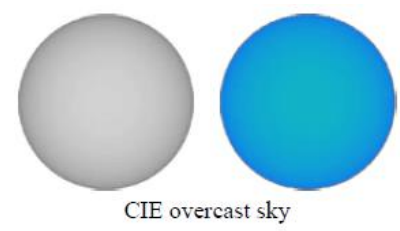

Gambar 3. Overcast Sky (langit mendung) (Sumber: Kensek dan Suk, 2011)

Tingkat pencahayaan alami untuk Indonesia yang berada pada garis Khatulistiwa adalah sebesar 10.000 lux. Hal ini juga sinkron dengan ketentuan perhitungan pencahayaan alami pada kondisi langit dalam SNI 03-2396 (2001). Untuk perhitungan diambil ketentuan bahwa tingkat pencahayaan ini berasal dari keadaan langit yang merata terangnya (uniform luminance distribution).

Daylight factor merupakan rasio tingkat pencahayaan didalam ruangan dengan diluar ruangan (lapangan terbuka) dalam satuan persentase, sehingga faktor pencahayaan alami dapat di hitung melalui persamaan:

$D F=$ Ein $/$ Eext $\times 100 \%$

Keterangan:

$D F=$ Daylight Factor (\%), Ein=Tingkat pencahayaan didalam ruang (lux), Eext=Tingkat Pencahayaan diluar ruangan (lux)

Dalam menentukan bidang kerja pada simulasi, khususnya pada software Velux Visualizer 2.0 dilakukan dengan mengambil ukuran 0,50 meter dari sisi dinding jika bentuk ruang dalam keadaan persegi. Bidang kerja dihitung keseluruhannya jika ruang yang disimulasikan memiliki bentuk yang tidak teratur. Hal ini berbeda dengan pengukuran manual dikarenakan dengan simulasi kita dapat menjangkau keseluruhan ruangan. Untuk ketinggian bidang kerja, diambil titik ukur setinggi $0,75 \mathrm{~m}$ dari permukaan lantai sesuai dengan ketentuan dalam SNI 03-2396 (2001).

Tingkat pencahayaan sesuai dengan standar yang dibutuhkan sesuai dengan fungsi ruang yang terdapat pada gedung Prodi Arsitektur 
Universitas malikussaleh dan konversi menjadi nilai faktor pencahayaan alami menggunakan persamaan (1) diatas sesuai dengan kondisi tingkat pencahayaan luar ruangan pada daerah khatulistiwa dapat dilihat pada tabel berikut:

Tabel 1. Nilai daylight factor yang direkomendasikan sesuai dengan SNI

\begin{tabular}{lcc}
\hline Fungsi Ruang & $\begin{array}{l}\text { Tingkat } \\
\text { Pencahay } \\
\text { aan } \\
\text { (Lux= Ix) }\end{array}$ & $\begin{array}{l}\text { Daylight } \\
\text { Factor } \\
\text { (DF= \%) }\end{array}$ \\
\hline Kamar Mandi & 250 & 2,5 \\
Ruang Direktur & 350 & 3,5 \\
Ruang Kerja & 350 & 3,5 \\
Ruang Komputer & 350 & 3,5 \\
Ruang Rapat & 300 & 3,0 \\
Ruang Gambar & 750 & 7,5 \\
Ruang Kelas & 250 & 2,5 \\
Perpustakaan & 300 & 3,5 \\
Ruang Gambar & 750 & 7,5 \\
Ibadah & 200 & 2,0 \\
\hline Sumber: SNI 03-2396 (2001) dan Penulis, 2017
\end{tabular}

Variabel Penelitian yang akan diamati adalah, pertama, Faktor pencahayaan alami (DF), dengan mengukur dan menganalisa nilai $D F$ dan memaparkannya untuk dilakukan penyesuaian terhadap standarisasi yang ada. Kedua, Hasil nilai dari DF kemudian dibandingkan dengan standar yang ada dan memberikan solusi desain untuk ruangan yang tidak memenuhi standar agar memenuhi nilai DF.

\section{HASIL SIMULASI}

Simulasi yang dilakukan pada studi ini menggunakan data permodelan objek studi sesuai kondisi eksisting seperti warna ruang, ketinggian antar lantai yaitu 4 (empat) meter ukuran bukaan sesuai dengan hasil pengukuran langsung, jarak bangunan sekeliling sesuai dengan data pengukuran dan nilai transmisi kaca yang disimulasikan mirip dengan kondisi eksisting dengan grey glass nilai Tvis 0.609 untuk kaca bagian luar dan 0.222 untuk kaca ventilasi dalam ruangan (kaca koridor).Sementara, kondisi window wall ratio(WWR) eksisting adalah lantai satu 27,42 persen, lantai dua 28,25 persen dan lantai tiga 18,28 persen.

Gambar berikut menunjukkan objek hasil permodelan di Sketch Up sebelum dilakukan simulasi di Velux Visualizer 2.0. Pada model tersebut atap bangunan tidak berimplikasi pada penerimaan cahaya alami kedalam ruangan sehingga diabaikan dalam permodelan. Namun demikian bangunan sekeliling dimodelkan dengan benar karena berdampak pada penerimaan cahaya alami pada ruangan yang ada di gedung Prodi Arsitektur Universitas Malikussaleh.

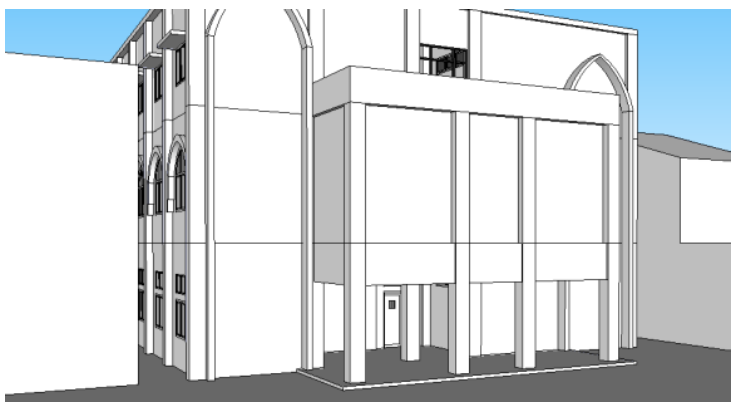

Gambar 4. Permodelan objek penelitian di Google Skecth Up 8.0

(Sumber: Penulis, 2017)

\section{Lantai 1}

Pada lantai 1 (satu) bangunan gedung Prodi Arsitektur terdapat 10 zona yang disimulasi. Beberapa zona tersebut diantaranya, ruang satpam, ruang dosen, gudang, dan sebagainya. Lantai satu ini merupakan bagian yang paling diperhatikan, karena banyaknya ruangan yang harus mendapatkan bantuan cahaya buatan. Berikut ini adalah hasil simulasi yang dilakukanpada lantai satu gedung Prodi Arsitektur.

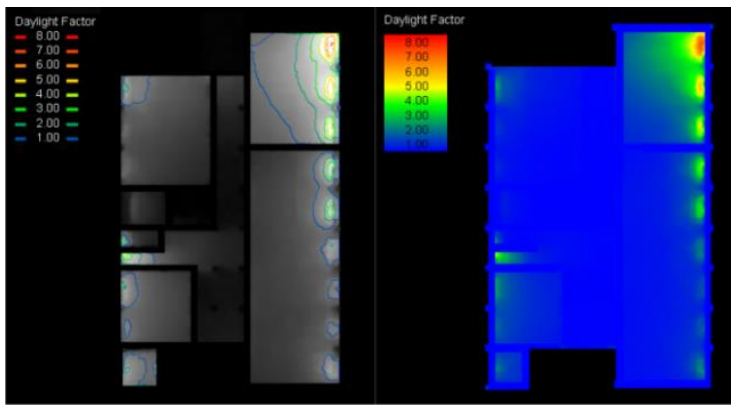

Gambar 5. Hasil simulasi iso contour dan false colour lantai 1 (satu)

(Sumber: Penulis, 2017)

Dari hasil simulasi tersebut didapatkan hasil serta persentase luas ruangan yang memenuhi standar sesuai SNI sebagai berikut: 
Tabel 2. Hasil simulasi lantai 1 (satu)

\begin{tabular}{|c|c|c|c|c|}
\hline $\begin{array}{l}\mathbf{N} \\
\mathbf{0}\end{array}$ & $\begin{array}{l}\text { Nama Ruang } \\
\text { (Zona) }\end{array}$ & 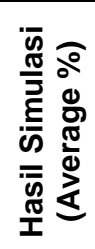 & $\begin{array}{l}\frac{\frac{\pi}{0}}{0} \\
\frac{c}{\frac{\pi}{d}} \\
\frac{\omega}{0}\end{array}$ & $\begin{array}{c}\text { Area } \\
\text { yang } \\
\text { memen } \\
\text { uhi } \\
\text { Standa } \\
r(\%)\end{array}$ \\
\hline 1 & $\begin{array}{l}\text { Ruang Satpam } \\
\text { (Zona 1) }\end{array}$ & 1,05 & 3,50 & 0,00 \\
\hline 2 & $\begin{array}{l}\text { Ruang ketua Prodi } \\
\text { dan Administrasi } \\
\text { (Zona 2) }\end{array}$ & 0,41 & 3,50 & 0,00 \\
\hline 3 & Gudang (Zona 3) & 0,53 & 1,00 & 17,43 \\
\hline 4 & $\begin{array}{l}\text { Ruang Tangga } \\
\text { (Zona 4) }\end{array}$ & 1,22 & 1,00 & 42,65 \\
\hline 5 & $\begin{array}{l}\text { Ruang Kuliah } 1 \\
\text { (Zona 5) }\end{array}$ & 0,34 & 2,50 & 0,00 \\
\hline 6 & $\begin{array}{l}\text { Ruang Studio } 1 \\
\text { (Zona 6) }\end{array}$ & 1,34 & 7,50 & 0,00 \\
\hline 7 & $\begin{array}{l}\text { Ruang Dosen (Zona } \\
\text { 7) }\end{array}$ & 0,48 & 3,50 & 0,00 \\
\hline 8 & $\begin{array}{l}\text { Koridor Lantai } 1 \\
\text { (Zona 8) }\end{array}$ & 0,04 & 1,00 & 0,00 \\
\hline 9 & $\begin{array}{l}\text { Kamar Mandi } \\
\text { Dosen/ Karyawan } \\
\text { (Zona 9) }\end{array}$ & 0,45 & 2,50 & 0,00 \\
\hline $\begin{array}{l}1 \\
0\end{array}$ & $\begin{array}{l}\text { Kamar Mandi } \\
\text { Mahasiswa Lantai } 1 \\
\text { (Zona 10) }\end{array}$ & 0,00 & 2,50 & 0,00 \\
\hline
\end{tabular}

\section{Lantai 2}

Hasil simulasi pada lantai dua sudah menunjukkan beberapa ruangan sudah mendapatkan porsi cahaya alami yang memenuhi standar. Visual hasil simulasi lantai dua dapat dilihat pada gambar berikut:

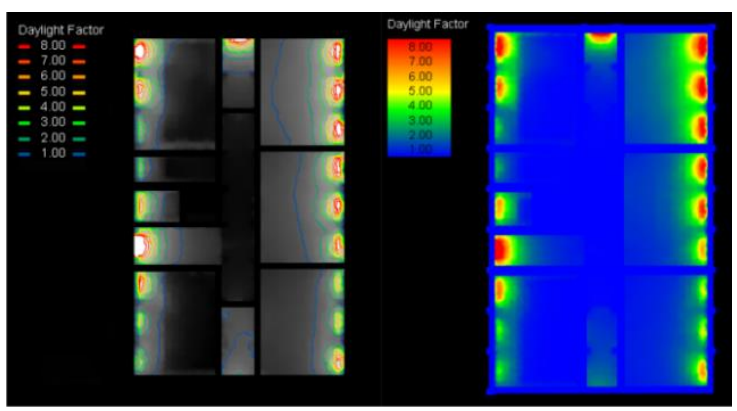

Gambar 6. Hasil simulasi iso contour dan false colour lantai 2 (dua)

(Sumber: Penulis, 2017)

Data ruangan yang telah memenuhi standar dapat dilihat pada tabel berikut:
Tabel 3. Hasil simulasi lantai 2 (dua)

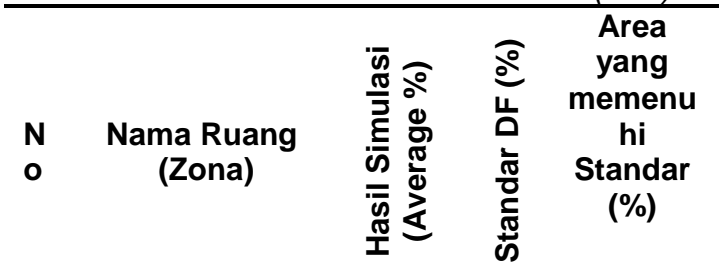

\begin{tabular}{|c|c|c|c|c|}
\hline 1 & $\begin{array}{l}\text { Ruang } \\
\text { Komputasi } \\
\text { (Zona 11) }\end{array}$ & 0,99 & 3,50 & 3,60 \\
\hline 2 & $\begin{array}{l}\text { Mushalla } \\
\text { (Zona 12) }\end{array}$ & 2,51 & 2,00 & 48,82 \\
\hline 3 & $\begin{array}{l}\text { Perpustakaan } \\
\text { (Zona 13) }\end{array}$ & 0,42 & 3,00 & 0,00 \\
\hline 4 & $\begin{array}{l}\text { Ruang Kuliah } \\
\text { 2A (Zona 14) }\end{array}$ & 1,66 & 2,50 & 16,46 \\
\hline 5 & $\begin{array}{l}\text { Ruang Kuliah } \\
\text { 2B (Zona 15) }\end{array}$ & 2,00 & 2,50 & 25,31 \\
\hline 6 & $\begin{array}{l}\text { Ruang Studio } \\
\text { Desain } \\
\text { Arsitektur } \\
\text { Akhir } 1 \text { (Zona } \\
\text { 16) }\end{array}$ & 1,49 & 3,00 & 10,89 \\
\hline 7 & $\begin{array}{l}\text { Ruang Studio } \\
\text { Desain } \\
\text { Arsitektur } \\
\text { Akhir } 2 \text { (Zona } \\
17 \text { ) }\end{array}$ & 0,88 & 3,00 & 2,78 \\
\hline 8 & $\begin{array}{l}\text { Ruang Asisten } \\
\text { Lab } \\
\text { (Zona 18) }\end{array}$ & 1,07 & 3,50 & 0,00 \\
\hline 9 & $\begin{array}{l}\text { Ruang } \\
\text { Himpunan } \\
\text { (Zona 19) }\end{array}$ & 1,85 & 2,50 & 23,63 \\
\hline 10 & $\begin{array}{l}\text { Koridor Lantai } \\
2 \text { (Zona 20) }\end{array}$ & 0,03 & 1,00 & 0,00 \\
\hline 12 & $\begin{array}{l}\text { Ruang Tangga } \\
\text { Lantai } 2 \\
\text { (Zona 21) }\end{array}$ & 2,30 & 1,00 & 55,21 \\
\hline 13 & $\begin{array}{l}\text { Kamar Mandi } \\
\text { Lantai } 2 \\
\text { (Zona 22) }\end{array}$ & 0,00 & 2,50 & 0,00 \\
\hline
\end{tabular}

Sumber: Penulis, 2017

\section{Lantai 3}

Hasil simulasi pada lantai tiga sebenarnya sudah menunjukkan profil penerimaan cahaya alami yang lebih baik, namun, karena standar ruangan yang terdapat pada lantai tiga seperti studio dan workshop membutuhkan penerimaan cahaya alami yang lebih besar sehingga sebahagian besar juga belum memenuhi standar yang ditetapkan. Gambar berikut menunjukkan hasil simulasi pada lantai 3 (tiga). 


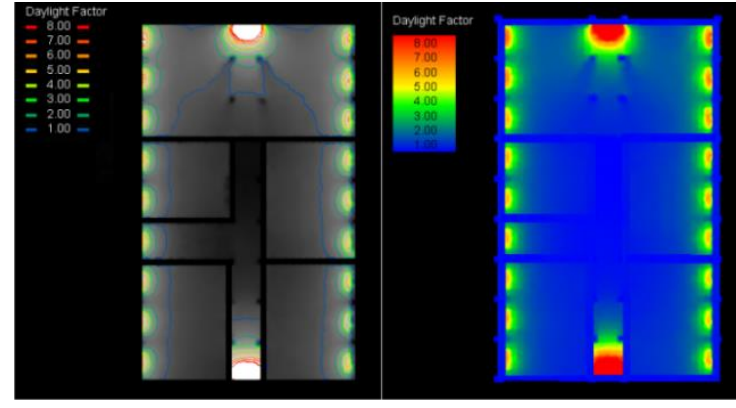

Gambar 8. Hasil simulasi iso contour dan false color lantai 3 (tiga)

(Sumber: Penulis, 2017)

Sementara, persentase luas ruangan yang memenuhi standar dapat dilihat pada tabel berikut:

Tabel 4. Hasil simulasi lantai 3 (tiga)

\begin{tabular}{|c|c|c|c|c|}
\hline $\begin{array}{l}\mathbf{N} \\
\mathbf{0}\end{array}$ & $\begin{array}{l}\text { Nama Ruang } \\
\text { (Zona) }\end{array}$ & 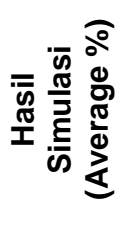 & 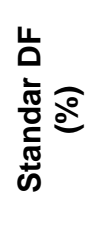 & $\begin{array}{c}\text { Area } \\
\text { yang } \\
\text { memen } \\
\text { uhi } \\
\text { Standa } \\
r(\%)\end{array}$ \\
\hline 1 & $\begin{array}{l}\text { Ruang Studio } \\
\text { Arsitektur 3B } \\
\text { (Zona 23) }\end{array}$ & 1,12 & 7,50 & 0,00 \\
\hline 2 & $\begin{array}{l}\text { Ruang Kuliah } \\
\text { 3A (Zona 24) }\end{array}$ & 1,08 & 2,50 & 9,35 \\
\hline 3 & $\begin{array}{l}\text { Ruang Studio } \\
\text { 3A (Zona 25) }\end{array}$ & 1,73 & 7,50 & 1,50 \\
\hline 4 & $\begin{array}{l}\text { Ruang } \\
\text { Workshop (Zona } \\
\text { 26) }\end{array}$ & 1,09 & 2,50 & 8,26 \\
\hline 5 & $\begin{array}{l}\text { Ruang Kuliah } \\
\text { 3B (Zona 27) }\end{array}$ & 1,04 & 2,50 & 7,12 \\
\hline 6 & $\begin{array}{l}\text { Koridor Lantai } 3 \\
\text { (Zona 28) }\end{array}$ & 1,46 & 1,00 & 24,00 \\
\hline 7 & $\begin{array}{l}\text { Ruang Tangga } \\
\text { Lantai } 3 \\
\text { (Zona 29) }\end{array}$ & 1,39 & 1,00 & 46,01 \\
\hline
\end{tabular}

\section{PEMBAHASAN}

Dari hasil simulasi diatas ada beberapa hal yang mirip penyebab terjadinya ketidakmerataan penerimaan cahaya alami pada ruang-ruang dari lantai satu sampai dengan lantai tiga. Pertama, kedalaman ruang dengan ukuran bukaan yang ada tidak mampu mendistribusi cahaya alami secara merata pada ruangan. Menurut Lechner kedalaman yang ideal untuk mendapatkan cahaya alami yang optimal dari bukaan di dinding adalah 15 kaki (kurang lebih 4,50 meter) [4]. Sementara pada gedung PAFT mayoritas ruang seperti ruang belajar studio dan perpustakaan memiliki kedalaman ruang sebesar 7,10 meter. Untuk ruang sirkulasi hanya ruang tangga saja yang bisa mencapai angka diatas $40 \%$ untuk area yang memenuhi standar pencahayaan alami dengan kedalaman ruang 5,50 meter. Semua koridor dari lantai satu sampai lantai tiga mengalami masalah kedalaman ruang 10,15 meter, sehingga mereduksi dengan signifikan akses cahaya alami dari bukaan yang ada pada dinding. Hanya ruang mushalla saja yang memiliki kedalaman ruang yang relatif kecil yaitu 3,50 meter. Penerimaan cahaya alami yang memenuhi standar pada ruang mushalla ini mencapai $48,82 \%$ dengan ukuran bukaan eksisting yang ada.

Kedua, keadaanWWR eksisting merupakan salah satu faktor penting yang menyebabkan ketidakmerataan penerimaan cahaya alami dengan kedalaman ruang besar pada gedung PAFT. Luas bukaan dibawah 30 persen pada lantai satu dan dua dinilai memperburuk penerimaan cahaya alami kedalam ruangan dengan kondisi tapak yang sempit dan dikelilingi oleh bangunan perimeter dengan jarak yang sangat dekat.

Ketiga, penghalang bangunan dalam hal ini bangunan disekeliling gedung PAFT yang terlalu dekat. Penghalang bangunan ini memiliki pengaruh penerimaan cahaya alami pada lantai satu dan dua. Sementara pada lantai tiga penghalang bangunan sudah tidak ada pengaruh disebabkan gedung PAFT lebih tinggi dari bangunan sekeliling. Kondisi penghalang bangunan ini merupakan hal yang tidak dapat dimodifikasi. Dengan kondisi penghalang bangunan yang relatif dekat, seharusnya penataan ruang pada lantai satu dan dua menjadi perhatian utama sehingga bisa optimal terhadap penerimaan sinar matahari.

Keempat, tingkat ketransparanan kaca yang digunakan terlalu gelap untuk bisa memasukkan cahaya alami lebih banyak kedalam ruangan. Grey glass dengan nilai transmittance kaca 0,609 dan 0,222 yang digunakan pada gedung PAFT merupakan masalah yang terkait dengan pemilihan material yang salah untuk pendistrbusian cahaya alami kedalam ruangan dengan kondisi penghalang bangunan yang ada.

Kelima, penataan ruang yang belapis dari akses cahaya matahari. Kondisi ruang dalam ruang ini adalah kondisi terburuk yang didapatkan pada gedung PAFT terhadap penerimaan sinar matahari. Walau terdapat usaha untuk memasukkan cahaya lewat bukaan atas (high window) namun usaha tersebut tidak berpengaruh sama sekali 
terhadap distribusi cahaya kedalam ruangan. Penggunaan kaca gelap pada bukaan interior dengan nilai Tvis0,222 adalah pilihan yang tidak tepat, karena kondisi kaca tersebut menghalangi lebih banyak cahaya yang masuk. Kondisi seperti ini ditemukan pada kamar mandi yang ada pada gedung PAFT.

Keenam, dengan kondisi penghalang bangunan yang ada, penerimaan cahaya alami juga diperburuk dengan pemilihan warna interior yang kurang tepat. Ada beberapa ruangan yang memiliki warna yang cenderung meredupkan ruangan, misal di ruang laboratorium komputer, ruang perpustakaan dan beberapa ruang kuliah di lantai dua dan tiga. Kondisi warna yang ada tersebut berpengaruh dari refleksi pada ruangan interior sehingga butuh usaha untuk mengganti dengan warna yang lebih baik dalam hal refleksi cahaya.

\section{KESIMPULAN}

Dari hasil simulasi dapat disimpulkan bahwa mayoritas ruang-ruang yang terdapat pada gedung PAFT tidak memenuhi standar pencahayaan alami yang ditetapkan dalam Standar Nasional Indonesia (SNI). Hanya sebagian ruang yang memiliki porsi cahaya alami yang memadai seperti ruang tangga pada lantai satu sampai lantai tiga diatas $40 \%$ luas ruangan dan mushalla pada kisaran $48 \%$ dari luas ruangan. Kondisi tersebut tentunya akan menimbulkan permasalahan pemborosan energi, performa visual, produktifitas, performa kerja maupun kesehatan dari pengguna gedung PAFT. Permasalahan ini tentunya harus bisa diselesaikan sehingga tidak terjadi dalam waktu yang lebih lama lagi.

\section{REKOMENDASI}

Dari permasalahan-permasalahan yang menghalangi distribusi cahaya alami kedalam ruang-ruang gedung PAFT maka ada beberapa solusi yang mungkin dilakukan dengan mempertimbangkan feasibilitas keterbangunan dengan dana yang efisien. Untuk masalah kedalaman ruang, penghalang bangunan dan penataan ruang tidak banyak dapat dilakukan modifikasi untuk pengoptimalan cahaya matahari kedalam ruangan. Sedangkan, luas bukaan, transparansi kaca dan warna interior merupakan hal-hal yang menyediakan peluang untuk pengoptimalan cahaya matahari kedalam bangunan.
Pada gedung PAFT untuk luas bukaan masih bisa dilakukan dengan memperbesar nilai WWR dan menambah bukaan pada sisi timur dan barat gedung. WWR untuk lantai satu diperbesar menjadi 38,39 persen, lantai dua 32,55 persen dan lantai tiga dengan kondisi tidak terhalangi nilai WWR cukup 21,19 persen saja. Membesarkan nilai WWRakan berpotensi untuk menimbulkan silau pada ruangan sehingga dibutuhkan penambahan shading devices pada beberapa ruangan yang tidak mendapat penghalang cahaya matahari yang cukup seperti pada lantai tiga dan sisi barat gedung PAFT. Sementara, untuk transparansi material kaca bisa mengganti seluruh kaca dengan jenis kaca bening yang memiliki nilai Tvis 0,850. Selanjutnya, warna interior ruangan diganti dengan warna yang bisa memberikan refleksi yang tinggi yaitu warna putih.

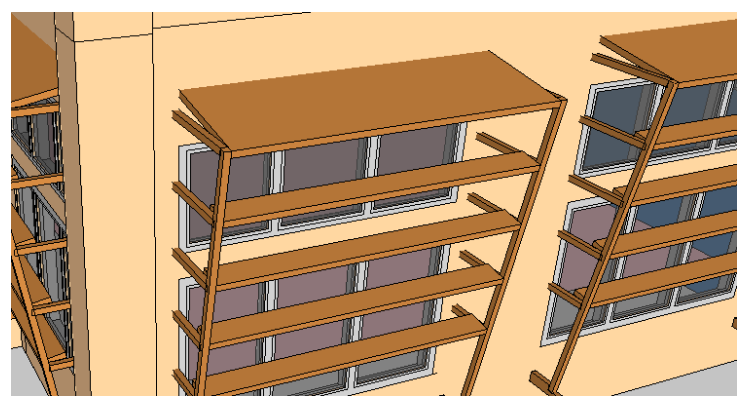

\section{Gambar 8. Usulan shading devices} (Sumber: Penulis, 2017)

Dengan mengimplementasikan rekomendasi desain tersebut, pada lantai satu, area yang dapat ditingkatkan penerimaan cahaya alami berkisar dari yang paling rendah dari $0,00 \%$ menjadi $4,49 \%$ pada ruang ketua prodi dan yang paling tinggi $17,43 \%$ menjadi $100 \%$ (peningkatan $82,57 \%$ ) pada ruang tangga. Variasi ini didapatkan karena perbedaan letak ruangan yang terpengaruh dengan kondisi eksisting bangunan sekeliling. Sementara, pada ruang kegiatan perkuliahan di lantai satu luas ruangan yang dapat memenuhi standar berhasil ditingkatkan dari yang paling rendah pada ruang studio 1 dari $0,00 \%$ menjadi $8,43 \%$ dan paling tinggi pada ruang kuliah 1 dari $0,00 \%$ menjadi $35,93 \%$. Ruang dosen hanya mampu ditingkatkan area yang memenuhi standar dari $0,00 \%$ menjadi $12,77 \%$. Profil luas ruangan lengkap lantai 1 yang berhasil dioptimalkan dapat dilihat pada tabel berikut: 
Tabel 5. Persentase ruangan yang memenuhi standar sebelum dan setelah rekomendasi pada lantai satu

\begin{tabular}{|l|l|l|}
\hline \multicolumn{1}{|c|}{ NAMA RUANG } & \multicolumn{2}{|c|}{$\begin{array}{c}\text { YUAS RUANGAN } \\
\text { MEMENUHI } \\
\text { STANDAR (\%) }\end{array}$} \\
\cline { 2 - 3 } & $\begin{array}{c}\text { SEBEL } \\
\text { UM }\end{array}$ & $\begin{array}{c}\text { REKO } \\
\text { MEND } \\
\text { ASI }\end{array}$ \\
\hline \multicolumn{2}{|l|}{ LANTAI 1 } & 9,76 \\
\hline Ruang Satpam (Zona 1) & 0,00 & 4,49 \\
\hline $\begin{array}{l}\text { Ruang ketua Prodi dan } \\
\text { Administrasi (Zona 2) }\end{array}$ & 0,00 & 30,64 \\
\hline Gudang (Zona 3) & 17,43 & 100,00 \\
\hline Ruang Tangga (Zona 4) & 17,43 & 35,93 \\
\hline Ruang Kuliah 1 (Zona 5) & 0,00 & 8,43 \\
\hline Ruang Studio 1 (Zona 6) & 0,00 & 12,77 \\
\hline Ruang Dosen (Zona 7) & 0,00 & 0,00 \\
\hline Koridor Lantai 1 (Zona 8) & 0,00 & 2,01 \\
\hline $\begin{array}{l}\text { Kamar Mandi Dosen/ } \\
\text { Karyawan (Zona 9) }\end{array}$ & 0,76 & 0,00 \\
\hline $\begin{array}{l}\text { Kamar Mandi Mahasiswa } \\
\text { Lantai 1 (Zona 10) }\end{array}$ & 0,00 & \\
\hline Sumber: Penulis, 2017 &
\end{tabular}

Sumber: Penulis, 2017

Pada lantai dua, ruang-ruang yang digunakan untuk kegiatan perkuliahan dan kegiatan yang membantu perkuliahan semuanya mengalami peningkatan luas ruangan yang memenuhi standar cahaya alami. Ada dua ruangan yang mengalami peningkatan paling rendah yaitu Ruang Studio Desain Arsitektur Akhir 1 dari $10,89 \%$ menjadi $28,00 \%$ dan perpustakaan dari $0,01 \%$ menjadi $17,96 \%$. Ruang kuliah 2B mengalami peningkatan yang sangat signifikan dari $25,31 \%$ menjadi $94,27 \%$. Luas ruangan yang berhasil dioptimalkan lengkap pada lantai dua dapat dilihat pada tabel berikut:

Tabel 6. Persentase ruangan yang memenuhi standar sebelum dan setelah rekomendasi pada lantai dua

\begin{tabular}{|l|l|c|}
\hline \multicolumn{1}{|c|}{ NAMA RUANG } & \multicolumn{1}{|c|}{$\begin{array}{c}\text { YUANG RUANGAN } \\
\text { MEMENUHI } \\
\text { STANDAR (\%) }\end{array}$} \\
\cline { 2 - 3 } & $\begin{array}{c}\text { SEBEL } \\
\text { UM }\end{array}$ & $\begin{array}{c}\text { REKO } \\
\text { MEND } \\
\text { ASI }\end{array}$ \\
\hline LANTAI 2 & 3,60 & 27,09 \\
\hline $\begin{array}{l}\text { Ruang Komputasi (Zona } \\
\text { 11) }\end{array}$ & 48,82 & 58,60 \\
\hline Mushalla (Zona 12) & 0,01 & 17,96 \\
\hline Perpustakaan (Zona 13) & 16,46 & 63,83 \\
\hline $\begin{array}{l}\text { Ruang Kuliah 2A (Zona } \\
\text { 14) }\end{array}$ & 25,31 & 94,27 \\
\hline $\begin{array}{l}\text { Ruang Kuliah 2B (Zona } \\
\text { 15) }\end{array}$ & 10,89 & 28,00 \\
\hline $\begin{array}{l}\text { Ruang Studio Desain } \\
\text { Arsitektur Akhir 1 (Zona } \\
\text { 16) }\end{array}$ & & \\
\hline $\begin{array}{l}\text { Ruang Studio Desain } \\
\text { Arsitektur Akhir 2 (Zona }\end{array}$ & 2,78 & 34,17 \\
\hline
\end{tabular}

\begin{tabular}{|l|l|l|}
\hline \multicolumn{1}{|c|}{ NAMA RUANG } & \multicolumn{2}{|c|}{$\begin{array}{c}\text { LUS RUANGAN } \\
\text { MEMENUHI } \\
\text { STANDAR (\%) }\end{array}$} \\
\cline { 2 - 3 } & $\begin{array}{c}\text { SEBEL } \\
\text { UM }\end{array}$ & $\begin{array}{c}\text { REKO } \\
\text { MEND } \\
\text { ASI }\end{array}$ \\
\hline 17$)$ & 0,00 & 21,82 \\
\hline $\begin{array}{l}\text { Ruang Asisten Lab } \\
\text { (Zona 18) }\end{array}$ & 23,63 & 51,05 \\
\hline $\begin{array}{l}\text { Ruang Himpunan (Zona } \\
\text { 19) }\end{array}$ & 0,00 & 0,00 \\
\hline Koridor Lantai 2 (Zona 20) & 55,21 & 100,00 \\
\hline $\begin{array}{l}\text { Ruang Tangga Lantai 2 } \\
\text { (Zona 21) }\end{array}$ & 0,00 & 0,00 \\
\hline $\begin{array}{l}\text { Kamar Mandi Lantai 2 } \\
\text { (Zona 22) }\end{array}$ & & \\
\hline
\end{tabular}

Sumber: Penulis, 2017

Pada lantai tiga, ruang studio arsitektur 3B yang merupakan studio paling luas di gedung PAFT hanya mampu memenuhi $11,10 \%$ saja standar cahaya alami yang ditetapkan. Hal ini disebabkan kedalaman ruang yang sangat dalam sehingga bagian terdalam tidak mampu dicapai oleh cahaya alami dari jendela. Porsi yang memenuhi standar pencahayaan hanya terdapat disekitar bukaan. Sementara ruang workshop berhasil merubah area yang memenuhi standar secara signifikan dari $8,26 \%$ menjadi 47,49\%. Ruang studio 3A mengalami perubahan yang tidak begitu signifikan dari $1,50 \%$ menjadi 9,42\%. Kedalaman ruang menjadi penyebab utama tidak merata distribusi cahaya alami. Tabel berikut memberikan informasi lengkap tentang situasi yang terjadi pada lantai 3:

Tabel 7. Persentase ruangan yang memenuhi standar sebelum dan setelah rekomendasi pada lantai tiga

\begin{tabular}{|l|l|c|}
\hline \multicolumn{1}{|c|}{ NAMA RUANG } & \multicolumn{2}{|c|}{$\begin{array}{c}\text { YANG } \\
\text { MEMENUHI } \\
\text { STANDAR (\%) }\end{array}$} \\
\cline { 2 - 3 } & $\begin{array}{c}\text { SEBEL } \\
\text { UM }\end{array}$ & $\begin{array}{c}\text { REKO } \\
\text { MEND } \\
\text { ASI }\end{array}$ \\
\hline LANTAI 3 & 0,00 & 11,10 \\
\hline $\begin{array}{l}\text { Ruang Studio Arsitektur } \\
\text { 3B (Zona 23) }\end{array}$ & 38,37 \\
\hline $\begin{array}{l}\text { Ruang Kuliah 3A (Zona } \\
\text { 24) }\end{array}$ & 9,35 & 9,42 \\
\hline $\begin{array}{l}\text { Ruang Studio 3A (Zona } \\
\text { 25) }\end{array}$ & 1,50 & 47,49 \\
\hline $\begin{array}{l}\text { Ruang Workshop (Zona } \\
\text { 26) }\end{array}$ & 8,26 & 68,98 \\
\hline $\begin{array}{l}\text { Ruang Kuliah 3B (Zona } \\
\text { 27) }\end{array}$ & 7,12 \\
\hline $\begin{array}{l}\text { Koridor Lantai 3 } \\
\text { (Zona 28) }\end{array}$ & 24,00 & 30,74 \\
\hline $\begin{array}{l}\text { Ruang Tangga Lantai 3 } \\
\text { (Zona 29) }\end{array}$ & 46,01 & 68,56 \\
\hline Sumber: Penulis, 2017 & &
\end{tabular}


Untuk kasus lantai tiga bisa dibuat memenuhi standar pencahayaan dengan menambahkan bukaan pada bagian atas (skylight). Namun, butuh penelitian lanjutan untuk dapat memastikan bagaimana skylight dapat membantu penyebaran cahaya alami yang merata, tidak menimbulkan silau, tidak menyebabkan panas berlebihan dan memenuhi standar yang ditetapkan dalam SNI pada lantai tiga gedung PAFT.

\section{DAFTAR PUSTAKA}

[1] Mediastika, C. E. (2013). Hemat Energi dan Lestari Lingkungan Melalui Bangunan. Yogyakarta: CV Andi Offset.

[2] Mahaputri, H. E. (2010). Studi Simulasi Model Penerangan Alami (Daylighting) Ruang Pada Bangunan Fasilitas Pendidikan Tinggi Dengan Superlite 2.0. Teknologi Dan Kejuruan 33(2) , 2012010.

[3] Lippsmeier, G. (1997). Tropenbau: Building In the Tropics. In I. W. Indarto, Bangunan Tropis. Jakarta: Erlangga.

[4] Lechner, N. (2007). Heating, Cooling, Lighting: Design Methodscfor Architects. In S. Siti, Heating, Cooling, Lighting: Metode Desain Untuk Arsitektur. Jakarta: PT Raja Grafindo Persada.

[5]SNI 03-2396-2001(2001). Tata Cara Perancangan Sistem Pencahavaan Alami Pada Bangunan. Jakarta: Badan Standarisasi Nasional.

[6] Chandra, T., \& Amin, A. R. (2013). Simulasi Pencahayaan Alami Dan Buatan Dengan Ecotect Radiance Pada Studio Gambar. Jurnal Arsitektur Komposisi 10(3) , 171181.

[7] Yuniar, E., Dwicahyo, S., J. Harmanda, S., K.Putra, D., \& R. Wijaya, F. (2014). Kajian Pencahayaan Alami pada Bangunan Villa Isola Bandung. Jurnal Reka Karsa 1(2) , 1-11.

[8] Samodra, F. T. (2011). Simulasi Penerangan Alam Bangunan Pendidikan. Seminar Nasional II: The Aplication of Technology Toward A Better Life (pp. 4147). Surabaya: Jurusan Arsitektur Institut Teknologi Sepuluh Nopember.

[9]Nurhaiza, N., \& Lisa, N. P. (2016). Optimalisasi Pencahayaan Alami Pada Ruang, Studi Kasus Gedung Prodi Arsitektur Universitas Malikussaleh. Arsitekno 7 (7), 33-42.

[10] Groat, L., David, W. (2013). Architectural research methods.-Second Edition. New Jersey: John Wiley \& Sons.
[11] Labayrade, R., Jensen, H. W., \& Jensen, C. (2009). Validation Of Velux Daylight Visualizer 2. Eleventh International IBPSA Conference (pp. 1506-1513). Glasgow, Scotland: IBPSA.

[12] Iversen, A., Roy, N., Hvass, M., Jorgensen, M., Christoffersen, J., Osterhaus, W., et al. (2013). Daylight Calculations In Practice (An investigation of the ability of nine daylight simulation programs to calculate the daylight). Copenhagen: Danish Building Research Institute, Aalborg University.

[13] Kensek, K., \& Suk, J. Y. (2011). Daylight Factor (Over Sky) versus Daylight Availability (Clear Sky) in Computer-based Daylighting Simulations. Journal of Creative Sustainable Architecture \& Built Environment, $C S A B E(1)$, 3-14. 
